\title{
Congenital Rubella
}

National Cancer Institute

\section{Source}

National Cancer Institute. Congenital Rubella. NCI Thesaurus. Code C34992.

A condition, whose clinical manifestations include intrauterine growth restriction, petechial rash, jaundice, generalized lymphadenopathy, hepatosplenomegaly, peripheral pulmonary stenosis, cataracts, and sensorineural deafness, that is caused by fetal exposure to the rubella virus during the first trimester of pregnancy. 